\title{
Accountability and development? Supporting provider-led evaluation of short- term community social-change projects
}

\section{Sarah Appleton-Dyer and Adrian Field}

Evaluating the outcomes of social-change initiatives is often conceptualised as a long-term endeavour, where the impacts take some years to assess. This is feasible for large-scale, multiyear initiatives, but challenging for relatively small-scale, community-based projects with short-term funding cycles. This article discusses the evaluation techniques developed to work with a range of short-term community projects funded through two national social-change campaigns to address bullying, and the exclusion of disabled people, in Aotearoa New Zealand. Drawing primarily on developmental evaluation and supported by results-based accountability (RBA), the evaluators provided evaluation support and capability building to community projects to support their development journeys and accountability requirements. We draw on our reflections and learning to identify the value of this approach, as well as the challenges and tensions that emerged from integrating developmental evaluation and RBA. Implications for practice are highlighted through these discussions. 


\section{Introduction}

An extensive amount of the evaluation literature identifies the importance of using indicators and outcome measures to identify whether a programme is on track and achieving its intended benefits (Poister, 2003; Shadish, Cook, \& Leviton, 1991; Wholey, Abramson, \& Bellavita, 1986). These indicators and measures can be particularly useful when supporting programmes to show their value within the accountability requirements and time frames of funders. Although often feasible for well established or clearly defined programmes and services, it can be challenging to carry out these practices with emergent and dynamic approaches to achieving change.

Many project innovators are seeking to learn as projects are implemented, and they do not have a clearly defined theory of change from the outset (Preskill \& Beer, 2012). Both factors can make it difficult to identify a concrete set of indicators and outcomes to measure. Traditional formative and summative approaches to evaluation can struggle to meet the evaluation and learning needs of such initiatives (Patton, 2011; Brennan, 2013) for similar reasons (e.g., as they are typically designed to test a theory of change). This challenge is confounded further when emergent and innovative approaches or projects are being implemented in complex environments (Patton, 2011). Evaluating the outcomes of social change, in particular, does not therefore lend itself well to traditional approaches to evaluation (Patton, 2011; Preskill \& Beer, 2012).

Social change can be defined as any significant alteration over time in societal behaviour patterns and cultural values and norms; that is, changes yielding profound social consequences, such as altered norms, values, cultural products, and symbols (Ministry of Social Development, 2014; Pinquart \& Silbereisen, 2004). Significant social changes are highly context-specific and they emerge and develop over 
time, with many also being long-term endeavours. Historical examples of social change include the Victorian public health movement (Szreter, 1988), the abolition of slavery (D’Anjou \& Van Male, 1998), the US civil-rights movement (Schama, 2009), and the suffragette movement (Keck \& Sikkink, 2000; McCammon, 2003). Some publicly funded initiatives seek to unleash the power of social change to tackle complex social problems which include family violence, attitudes to parenting, and how we think about mental illness and disability (Gravitas Research and Strategy, 2005; Point Research, 2010; Vaughan \& Hansen, 2004). These initiatives can, and often do, involve multiple activities and interventions in various combinations, targeted at different levels in a system. Commonly, many community-based projects are funded which focus on similar overall community- or system-level goals, but vary in many aspects, including their approach.

Initiatives which aim to address complex social problems are often emergent and dynamic and, as such, they develop and adapt over time. The level of uncertainty in these contexts is best suited to an evaluation approach that can support and embrace the adaptation and change which is inherent in community development and social change, such as developmental evaluation. Patton (2011) suggests that developmental evaluation can support such emerging innovations by facilitating adaptation within the context of complex realities. He also proposes that developmental evaluation can be particularly valuable to social innovators and those seeking to bring about major social change. Patton notes the non-linear pathways, ups and downs, tipping points, and critical-mass momentums of social change, and suggests that such chaos and unpredictability is not well catered for by traditional approaches to evaluation that seek to control and predict. In contrast, he describes developmental evaluation as embracing the turbulence of social change as it unfolds in the 
context of complexity. Developmental evaluation is responsive to the need for innovations to be adaptive and to respond to the realities of non-linear complex dynamics inherent in our society and systems (Patton, 2011).

The dynamic nature of social change and developmental evaluation appear to be well suited. However, when seed funding for social-change projects comes from public resources, the dynamic and emergent nature of these projects can come into conflict with traditional government planning and funding cycles that exist in Aotearoa New Zealand, as well as other countries. This can pose challenges to evaluators who are seeking to support projects to learn and adapt, while also providing funders with evidence on the value and results of their investment. This notion is supported by McDonald (2016) who identified the challenge of collecting reliable real-time feedback when adopting a developmental approach. Although there is much written on the value of adopting a developmental approach when evaluating dynamic and innovative initiatives (Patton, 2011; Preskill $\&$ Beer, 2012), there is less evidence on the challenges and success of achieving this within the context of the traditional funding cycles that many evaluators are faced with.

This article presents the evaluation approach and techniques adopted by the authors to respond to the challenges of evaluating innovative community development projects within the accountability requirements of the public sector. Specifically, this article draws on our work with a range of short-term community projects funded through two national social-change campaigns to address bullying, and the exclusion of disabled people, in Aotearoa New Zealand. We summarise the context of the projects and the evaluation. This summary is followed by an overview of the key evaluation theories and approaches that influenced our work, as well as some examples of the specific methods used to support the projects. Following this 
overview, we reflect on the value, and the challenges, of this approach in supporting the development of the community projects, and its implications for evaluation theory and practice.

\section{Context of projects}

\section{Funding and organisational settings}

The projects were funded through one of two social-change campaign funds: one fund was aimed at challenging attitudes and behaviours to disabled people; and the other at countering bullying of children and young people in the community and promoting prosocial behaviour (Ministry of Social Development, 2014; Ministry of Social Development, 2015). Projects supported by these funds were developed by a variety of organisations, including community and non-governmental organisations, as well as local government and social enterprises. Some projects were developed by standalone organisations, and some were established through alliances of organisations.

Common to all organisations was both a limited term of funding, and a relatively small level of funding for individual projects, ranging from $\$ 10,000$ to $\$ 100,000$. Project activities were generally expected to be completed within a one-year period. Each worked across multiple settings, contexts, and population groups. They encompassed such diverse activities as developing anti-bullying policies in sports clubs; building social enterprises led by disabled people; improving accessibility of marae, public services, and amenities; theatre productions; youth leadership development; and challenging attitudes to disabled people through church settings.

\section{Catalysing social change}

Complexity theory, which informs approaches to developmental evaluation, distinguishes between a) the simple, where the likely 
outcomes are known and the pathway between cause and effect is transparent; b) the complicated, where the interrelationships between elements are more challenging but can be solved through expert input; and c) the complex, where outcomes are less predictable, are significantly influenced by relationships between people and organisations, and an understanding of cause and effect is often only apparent in retrospect (Westley, Zimmerman, \& Patton, 2006). The participating projects are typical of social-change projects that are at the complex end of this spectrum. The projects all sought to create a shift in public thinking, to challenge deeply entrenched social norms (Appleton-Dyer \& Field, 2014). These norms reflect mental models that are based on well-established values and conceptions of the world, and alongside these, views of what may be acceptable attitudes and behaviours (Maani \& Cavana, 2007; Senge, 1990). From this complexity perspective, exclusionary attitudes to disabled people, and bullying in the community, can both be seen to be the product of long-held views and beliefs. These have normalised and perpetuated discriminatory and exclusionary behaviours (Levitas et al., 2007).

Challenging such norms requires actions at multiple levels, across familial, community, organisational, and societal settings. The social-change funds were set up to achieve this by funding projects to deliver a range of activities and interventions in several communities. There was recognition by the funder that the projects themselves would be working in a developmental space that is reflective and adaptive to needs and opportunities, and that learning from the projects would emerge as they progress. At the same time, the funders were seeking a clear understanding of the outcomes achieved by the individual projects. They did, however, recognise that outcomes would not be uniform across projects, and that some outcomes would be more intangible and take longer than a year to 
achieve (such as relationships and buy-in established between local agencies and organisations, and awareness of exclusion and bullying as local issues).

In this context, the role of the evaluation team was to support this developmental journey, in a way that enabled project leadership to reflect on their project design, development, challenges, learning, and outcomes. In particular, for these small-scale community projects, with limited evaluation experience and capacity, the evaluator's role was to support and enable a shift from reporting on outputs and activities, towards a focus on understanding achievements and outcomes. This focus was also important for enabling the evaluators to integrate the insights and data from these projects to provide feedback to support the development and learning of the two national funds.

\section{Guiding principles and method}

\section{Guiding principles}

\section{Results-based accountability}

The results-based accountability (RBA) framework developed by Mark Friedman (2005) is key to the work of funders. Part of our brief was to incorporate the principles of RBA into our evaluation activities. RBA encourages a distinction between two types of accountability: population (in this case, overarching goals sought by the agency); and performance (project-level delivery) (Friedman, 2005). The framework then focuses on three types of performance measures by guiding initiatives to explore the following key questions: How much did we do? How well did we do it? Is anyone better off? The RBA framework is generally valued for its simplicity and ability to provide guidance which communities, agencies, and teams can use to focus on results, or outcomes, to make a positive change for communities (Ryan \& Shea, 2012). 
In practice, the simplicity of the framework was useful for engaging community organisations and groups in understanding their projects and potential data-collection approaches, and for its alignment with the accountability and measurement frameworks of the funding organisation itself. However, we found the focus on performance measures tended to lead to a preference by project leaders for quantitative data over a richer understanding of context and broader systems, which are likely to be valuable when understanding social change. This tended to reflect the association that project leaders made between measurement and quantitative data. We often had to encourage projects to value their own reflections and insights when developing their evaluation plans.

As evaluators, we needed to support learning and development within both the projects and the funds, while also providing feedback that could support their accountability requirements. This can be challenging, as reflected in the literature on developmental evaluation (Brennan, 2014). Although we were well supported by the funders to support learning and improvement within the projects, the broader and more traditional accountability requirements to demonstrate value and changes in outcomes remained. Our direct experience in these projects led us to the view that the RBA framework assumes a more linear approach to implementation with no direct questioning that might encourage learning, adaptation, or change. Although this notion is not explored in the literature relating to RBA, we consider RBA to be more useful when understanding a clearly defined project rather than an innovative project that requires evaluation to support its creation and emergence. The RBA framework also gives little attention to the complexity of different contexts and the influence of context on the implementation and achievements of an initiative. These limitations, coupled with the funders' recognition that these projects were highly likely to be dynamic and 
adaptive, led us to draw primarily on the principles of developmental evaluation (discussed further below), referring to, and using, RBA as a framework for collecting data about outcomes.

\section{Developmental evaluation}

Developmental evaluation differs from traditional formative and summative evaluation. It adopts a much more real-time, learning-orientated approach to evaluation, and can be particularly useful in the early stages of an initiative (Brennan, 2013). Developmental evaluation has also been noted for its ability to provide "evaluative information and feedback to social innovators, and their funders and supporters, to inform adaptive development of change initiatives in complex dynamic environments" (Patton, McKegg, \& Wehipeihana (2015, p.v). This ability is well suited to the evaluation needs of the social-change campaigns and projects. This approach is also noted for its role in providing accountability for funders of social innovations (Patton, 2015).

The theory and practice of developmental evaluation is well established, dating back to at least the mid-1990s (Patton, 1994). Most recently, Patton (2015) has consolidated thinking into eight guiding principles of developmental evaluation. These are: having a developmental purpose; evaluation rigour; utilisation focus; innovation niche; complexity perspective; systems thinking; co-creation; and timely feedback. Each of these principles and the way they were reflected in our evaluation approach is described below.

1. A developmental purpose for project evaluations was important in this context, as it enabled us to inform and support the project teams' need to rapidly learn and refine their initiatives.

2. Evaluation rigour promotes the systematic nature of evaluation first through the use of evaluation techniques such as thinking evaluatively and applying evaluation logic; and secondly through 
the appropriate use of data-collection methods and analysis (Patton, 2015). This principle aligns well to the values of the evaluators and enhanced the robustness of the evaluations and their credibility, and supported us to draw on systematic approaches and techniques that could be taught or shared across all projects regardless of their social-change visions.

3. The utilisation-focus principle encourages evaluators to focus on the needs of intended users from start to finish. This principle aligned with the need to provide or support evaluation feedback that influences decision making and development.

4. Patton (2015) notes that "the arena where innovation is occurring, or at least being attempted, is the defining niche of developmental evaluation" (p. 304). The innovation niche for our work was the context of the two social-change campaigns led by the funding organisation. These were wide ranging, from sports centres to banks and district health boards. Innovation in these contexts meant many different things, although all were connected by their desire to reduce bullying or increase the social inclusion of disabled people.

5. The complexity-perspective principle highlights the need to "understand and interpret development through the lens of complexity" (Patton, 2015, p. 304). Patton suggests that this interpretation involves using complexity premises and dynamics when guiding innovation or adaptation, as well as when interpreting emergent findings. Insights gained through the application of the previous four principles supported us to understand and embrace the complexity perspective. As the projects developed and changed, so did the evaluation. At its simplest level, this required changes in data-collection tools or approaches. For some projects, however, adaptations to the evaluation focus and plan were required. 
6. Systems thinking encourages evaluators to be mindful of the interrelationships, perspectives, and boundaries within which the projects were seeking to create social change. Many of these projects were also seeking to create change through influencing these systems or the boundaries within them. Developmental evaluation supported the projects to conceptualise their work within this framing, and was also useful for highlighting the complexity of the social issues that they were seeking to influence.

7. Our ability to work alongside the projects and the funding organisation supported us to implement the co-creation principle. This refers to the idea of the evaluation becoming embedded within the innovation in a manner that supports the process of change and development (Patton, 2015). Although we did not co-create the innovations, we worked collaboratively with the funder and the individual projects to develop the innovations from the early stages of thinking, through to understanding the logic of their innovations, supporting their evaluation activities, and making sense of the emerging evidence. Building the evaluation skills and experience of the project leaders was also intended to support the notion of co-creation.

8. The use of timely feedback is the eighth principle identified by Patton (2015), and a characteristic of evaluation that is often identified as important (Appleton-Dyer, Clinton, McNeill \& Carswell, 2012). Timely feedback was important because project teams were applying innovative solutions to complex social problems and needed evaluation to support the development of their work, not just the identification of improvements (Patton et al., 2015). Our role was to provide timely feedback to the projects and funders; or to highlight the value of timely feedback or timely sense making with the project teams who were collecting their own data. 


\section{Epistemological considerations}

In terms of the developmental-evaluation theory and RBA framework guiding our approach to support the projects, it was important for us to recognise that weaving developmental evaluation through RBA had the potential to pose challenges or conflicts. RBA focuses on performance measurement, while developmental evaluation values reflection, and learning to shape initiatives as they are implemented and allow for outcomes to emerge (Friedman, 2005; Patton, 2011). We feel that it is helpful to provide the rationale for integrating these approaches when each could have been used alone.

The RBA framework was a requirement from the funding organisations who use it to support them in understanding their work and getting feedback from the projects that they fund. This framework was valuable, as the project teams were familiar with this approach. Although the simplicity is useful, we feel that this simplicity is also a key weakness of RBA. As noted above, the questions posed by RBA led project teams to focus on quantitative measures, which can limit the opportunity for rigorous evidence when dealing with small sample sizes and understanding social change. Arguably, innovative projects that are still being developed will benefit from the in-depth insights provided through qualitative data-collection methods, or ideally a mixed-methods approach. Understanding who is better off through RBA is useful for identifying if a project has made a difference or not. However, the question that this does not answer relates to values. Who is better off and according to whom? On what basis are we determining "better off"? Who should be better off? These questions and discussions are not facilitated through RBA, nor does RBA support insights designed to support adaptation and development. RBA does not encourage reflection on the value inherent in deciding who is better off.

Integrating the principles of developmental evaluation with this 
approach allowed us to engage with the projects with clear intentions on the developmental nature of evaluation, a focus on the intended use of findings, and the value of rapid feedback and sense making. The weaving together of RBA and developmental evaluation enabled us to support the projects' development and also encourage project staff to engage in robust data-collection and analytical techniques. RBA supported projects to develop data-collection processes to monitor what they were doing and the difference that this was making. Whereas, the developmental approach was used to provide projects with the flexibility to pursue areas of success and to let go of those activities that were not gaining momentum. The developmental-evaluation approach also encouraged project staff to recognise and reflect on the complexity and systems within which they were seeking to create change. This required a continual process of reflection to understand their journey. This was embraced by some projects more than others, as discussed later.

To achieve this, developmental evaluation was the overarching theory influencing our engagement with the projects with RBA supporting project members to develop a core set of measures that would help them to collect evaluation data and to make decisions to support their intended outcomes.

\section{Evaluation methods}

Funding was not available for intensive evaluation support to all projects. Instead, evaluation support was targeted to project leadership to help refine the design and delivery of their projects, and in particular the pathway from project development to social-change outcomes; support with data-collection design and analysis; and providing practical support to community projects in data collection. Given the context, our approach was pragmatic, focused on supporting project staff to evaluate some of their more immediate activities and changes, 
rather than the longer term vision of their social-change initiative. Table 1 details the range of activities undertaken.

Table 1. Evaluation capability building, mentoring, and support provided to projects

\begin{tabular}{|c|c|}
\hline Type of support & Activities available to projects \\
\hline Hui & $\begin{array}{l}\text { - An introduction to evaluation } \\
\text { - Theory of change } \\
\text { - Developing indicators } \\
\text { - } \text { Data-collection methods }\end{array}$ \\
\hline Targeted support & $\begin{array}{l}\text { - Site visits-theory of change and evaluation planning workshop } \\
\text { - Theory of change-intervention logic } \\
\text { - Survey design } \\
\text { - Semistructured interview guides } \\
\text { - Focus-group prompts } \\
\text { - Case-study guidance } \\
\text { - Review existing data-collection tools and processes } \\
\text { - Critical friend role }\end{array}$ \\
\hline Generic support & $\begin{array}{l}\text { - On-call evaluation advice and support } \\
\text { - Examples of data-collection tools developed for other projects } \\
\text { - Evaluation component of a social-change toolkit }\end{array}$ \\
\hline
\end{tabular}

\section{Regional hui}

In the first instance, evaluation capability building was provided in the form of training at a series of 2-day regional hui ${ }^{1}$ for participating projects, led by the funding organisation. At these hui, the evaluators worked with project leadership in a mixture of group and one-on-one training to develop an understanding of the underlying principles and application of evaluation, as well as the complexity of the issues they were confronting. Capability-building activities included supporting the development of programme theory for each project; identifying potential indicators of progress using results-based accountability as a frame; and discussion of potential data-collection tools. The intention was to demystify evaluation by highlighting its contribution to achieving project aims while at the same time giving practical guidance on approaches to self-evaluation for the various projects. The

1 A "hui" is a Māori term for a gathering or meeting, but which is also widely used for such events as seminars or conferences. 
approach was explicitly focused on providing practical guidance on approaches to evaluating the projects in a way that was context-specific and feasible for these community-based projects.

It should be noted that evaluation capability building was one strand among a range of activities on these 2-day hui. Other activities at these hui included training on understanding social change, presentations on each project by their leadership, and training on media engagement.

\section{Targeted data-collection design and analysis}

For a selection of projects, some in-depth support was provided, including site visits to meet with project leadership and work with them to develop detailed programme logic for their projects. A significant strand of activity was support with development of specific data-collection tools, including survey development, guidance on preparing case studies, data-analysis support, qualitative interview/focus-group guides, and critical appraisal of data-collection approaches developed by project leadership. An important element of this engagement was the recognition by both the evaluators and the funding agency that, with limited term and scale of project funding, the extent of evaluation activity which could be undertaken would be similarly limited. The support offered was therefore focused on developing simple and appropriate data-collection tools. In many cases there was a raft of existing data sources which could be applied to give some indication of buy-in and engagement to the projects locally, including local news-media uptake, feedback and engagement on social media, and unsolicited feedback received.

A common challenge was a desire in many projects to undertake pre-and post-intervention analyses to "prove" that change had occurred. For many reasons, pre- and post-intervention surveys were simply not feasible for these projects. These reasons included the 
feasibility of building appropriate designs and samples for data collection (particularly for community-wide initiatives with limited overall budgets) that might be able to attribute change to the intervention itself; as well as the willingness of the participants to take part in pre- and post-intervention surveys. Suggested alternatives to pre- and post-intervention measurement included exploring people's willingness to intervene in bullying situations as a result of a community workshop; reflections on changes in understanding on bullying and disability; observed changes in policy and practice in community settings (such as local facilities, sports clubs, and churches); self-reported changes in self-confidence and independence; and the viability or impact of community social enterprises.

Complementing the somewhat more tailored and in-depth evaluation support, the evaluation team also offered more generic evaluation support to projects, including on-call advice on refining data-collection approaches, development of some generic survey tools (with guidance on their use and appropriate settings); advice on potential non-survey data-collection opportunities; and making evaluation findings available on fund websites. The evaluator role also encompassed preparing a series of overarching evaluation reports for the funder to draw together and make sense of the findings across these multiple projects (see for example, Appleton-Dyer, Edirisuriya, Field, \& Boswell, 2015).

\section{Reflections}

We reflected on the value of developmental evaluation and RBA, as well as our experience of providing on-the-ground evaluation support to projects and supporting learning and accountability with the funder. We drew on feedback provided by the funders and the project leaders through direct contact, as well as online evaluation-feedback surveys. The surveys were used to identify the value of the support 
provided by the funders and evaluators. The funders and project leaders often noted the way in which the evaluation training and support was accessible and easy to follow. There was general agreement that our approach "demystified evaluation" for some of the projects, and created greater receptiveness to undertaking evaluation activity. This supported the project teams to understand the value of evaluation, and our hui activities and project support enabled them to identify some pragmatic approaches to evaluating and developing their projects. This was reflected in their engagement in evaluation and the feedback provided through the regular project team surveys.

Our approach was supported by the values and learning culture of the funders and most project leaders who were open to innovation and continuous learning, and to adapting to the complexity of the environment. The funders in particular sought to support continuous learning through identifying and acknowledging the need for adaptation, seeking regular feedback from the projects, and openly sharing this information. These have been identified as key success factors to a developmental evaluation (Preskill \& Beer, 2012), and were certainly crucial factors in supporting our approach.

\section{Bringing together RBA and developmental evaluation}

The RBA framework was useful for supporting project leaders to identify a core set of immediate measures or indicators (quantitative and qualitative) for specific activities. The measures were designed to be pragmatic and feasible, and were focused on the immediate activities planned as part of the projects, such as supporting a community event. These pragmatic measures ensured that the projects received timely data-based feedback on their activities that could be used to support discussions relating to their work to support learning and the refinement of their approach, as required. The framing of the RBA questions, however, often led projects to focus on quantitative data. 
This focus was at the cost of establishing qualitative insights that are useful for informing decisions on next steps and understanding the perspectives of those that they might be seeking to influence. This is a common problem in many spheres of activity where an over-reliance on quantitative measures can impede learning, change, and development (Meadows, 2008). We often needed to highlight the value of qualitative data in addressing the key questions of the RBA framework.

Project teams' focus on outcomes or perceived measures of change was influenced by the value attributed to outcome measurement and the preference for quantitative measures within the public sector, and arguably the RBA framework. The role of stakeholders in influencing evaluation is well noted in the literature (House, 1991), as is the influence of evaluation readiness on stakeholder engagement in evaluation (Clinton, 2001; Stockdill, Baizerman, \& Compton, 2002). Our experience suggests that the perceived value of specific approaches can also influence stakeholder engagement and, ultimately, the implementation of an evaluation and its use. Research on the influence of evaluation suggests that the perceived value of evaluation is enhanced through a participatory approach that is also technically sound and appropriately sophisticated (Appleton-Dyer, 2012). The interactions between the different project teams in the hui were useful for supporting discussions on the value of different types of evidence and the importance of ensuring methods were fit for purpose. However, this did not always translate into data collection for some of the projects. The emphasis on quantitative data was also influenced by their previous experiences of research methods or evaluation, with many being more familiar with surveys than capturing verbal feedback.

\section{Reflecting developmental-evaluation principles}

Adopting an approach influenced by developmental evaluation was crucial for supporting the evaluation in embracing the emergent and 
dynamic nature of the projects. Despite the 12-month time frame, the approach allowed us to recognise the uncertain nature of some of the projects, and this in turn provided comfort to the project leaders. More specifically, developmental evaluation allowed a level of uncertainty and exploration that supported the project teams in a developmental approach of refining and learning from their initial approaches to implementation. Many of the projects, for example, refined their approach to shifting attitudes and behaviours in their local communities. We often saw a shift from workshops with projects being delivered within the same geographical region to more valued contextualised conversations directly with project teams that provided greater relevance and value to those that they were trying to change or engage in their initiatives.

Developmental evaluation enabled us to work collaboratively with the funding organisation and the project teams. This enabled us to develop the evaluation capability of project teams and also support the development of their work. Although we sought to embed developmental evaluation in our approach, we must acknowledge the challenges of reflecting all its underlying principles. The projects were small in scale with variations in buy-in from project teams, and most were only implemented over approximately 9 to 12 months. As evaluators we were also developing our own knowledge and understanding of how best to build the capability of projects to embark on a developmental journey, and at times it was challenging to do this from a distance.

The utilisation-focus principle had a key benefit in the context of two national campaigns and multiple projects. It supported us to balance the requirements and intended use of the evaluation findings by the project teams and funding organisation. For example, the rapid feedback supported the project teams to adapt and develop their initiatives, while the ongoing tracking of process and outcome 
indicators supported the funding organisation to make decisions on the type of projects that they continued to fund to support their overarching vision.

The multifaceted nature of the issues that were targeted by the two funds lent themselves to an approach that embraced a complexity perspective. Systems thinking aligned well to the funding organisation's understanding of the need to look beyond individual projects or groups within society, to engage a diverse range of projects to support change across communities and systems. However, while we drew on this principle to support us in engaging with the funding organisation about the progress of the different types of projects, we did not have the opportunity to apply this principle fully with each project. Many were small in scale and did not always fully engage in the evaluation design or data collection, reducing the opportunity for rigorous evaluative discussions to support sense making through a complexity lens. This challenge was discussed with the funders, as they sought to allocate funding towards, first, seed funding of a wide range of small-scale projects to see which ones would flourish and grow, and secondly, funding larger scale projects that enabled more dedicated staff time and resources. Although capacity was part of the challenge, the previous experience, networks, passion, and commitment of individual project leaders or teams were key success factors that also supported small-scale projects.

The co-creation principle was given expression through creating connections between the evaluation activities and the development of the innovation; but this was similarly challenged by the size and scale of some projects, and the receptivity of their leadership to such input. Where possible, we would encourage project teams to engage with and gather feedback from their communities to refine and develop their innovation. This moved co-creation beyond the funder, project, and evaluation team to the community. 
The principle of timely feedback was important to many projects, although not all. Feedback was not about traditional data analysis and reporting, but rapid feedback to inform discussions and decision making. This process was particularly valuable for project teams who were willing to engage in rapid learning and adaptation cycles. It was more challenging for those who were more committed to a process that they found hard to change when it was not delivering all that they had intended.

\section{Supporting project-based evaluation}

Supporting teams to develop their own evaluation approaches was exciting, as it revealed a genuine desire within most projects to understand outcomes and engage in learning. This interest in evaluation was twofold. First, the project leaders recognised the innovative nature of their projects and were interested in using evaluation to generate timely feedback to support learning and development. Secondly, the project groups recognised the features, challenges, and enablers of the contexts within which they were trying to achieve social change. As much as the funders wished to understand impact, the project teams themselves were also eager to collect evidence that would support them in presenting their stories of change, outcomes, and development, and as evidence for future applications for funding. Some of the project leaders also suggested that the evaluation support and mentoring would support them to evaluate other projects.

The support available for the majority of projects, however, was restricted to the development of the evaluation plan and data-collection tools. These plans were designed to support the collection of robust high-quality and credible data, but this was not always the case. A small number of projects did not implement the evaluation plan as intended, and this impacted on the quality of the data available. For example, one project was seeking to identify the accessibility 
of a large community event. Part of their evaluation plan involved a survey that asked participants how accessible they found the venue in terms of physical and social accessibility. When we reviewed the data collected by the project team, it was found that the majority of respondents indicated that they had no accessibility needs, thus limiting the insights into the accessibility of the venue for disabled people. This highlighted the importance of ensuring that the data-collection plans are fully communicated to those who will be collecting the data, as the data collection was supported by a group of volunteers supporting a very small community-based organisation.

For evaluation practice, the projects would have benefited from more-intensive support with data analysis and interpretation than was available in the scope of work. Many of these projects were innovative, and the level and type of outcomes achieved were not always predictable. Analysis and interpretation is particularly challenging for innovative and dynamic projects. A developmental approach would advocate for greater engagement in the interpretation of the evaluation findings with each project (Patton, 2011; Preskill \& Beer, 2012). Although some projects connected with the evaluation team on this matter, the project leaders were largely responsible for this aspect of the evaluation and thus facilitating their own learning and adaptations. Providing this support would have bolstered the evaluation capability-building activities and support.

\section{Challenges of short-term projects}

The 12-month time frame for both the projects and the evaluation contributed to the limited ability for the projects and evaluation to demonstrate change in longer term outcomes. When reporting findings back to the funder, it was important to frame any feedback on the projects within the context of social change, complexity, and the realities of being able to demonstrate sustainable change within 
12 months. This challenge is reflected by Preskill and Beer (2012) when discussing the evaluation of social innovations. They call for a change in how funders think about and use evaluation. This includes adapting funding cycles to better reflect the spirit of trial and error that is at the heart of innovation. Our experience would support this notion. Real-time feedback and developmental processes should also be embedded early on. This would support the development and learning that allows projects to move towards their longer term outcomes, and ultimately maximise the value of their investment. For those tasked with providing stories of change within a shorter time frame, the use of indicators and short-term outcomes were useful for demonstrating that the projects were on the right track.

The 12-month time frame also challenged our ability to fully embrace a developmental approach. A developmental approach requires the evaluators to be available and supporting learning, adaptation, and change (Patton, 2011). Most project leaders were able to reflect and refine their approach in their initial stages, but some struggled to get engagement in or uptake of their projects. As a result, they were not able to engage in as many cycles of reflection as some of the other projects. This in part reflected the capacity for some of the project leaders to embrace a more developmental approach and to recognise the need to adapt and change to gain momentum; some were reluctant to do so. Having the level of resource available to provide more-intensive support to more projects may have supported more projects to fully engage in developmental evaluation with a view to unlocking its value. When interpreting this learning, it is useful to note that the challenge of supporting or achieving change in a 12-month time frame is not limited to a developmental approach (Diaz-Puente, Yague, \& Afonso, 2008). 


\section{Conclusions}

Developmental evaluation offers a valuable approach to the evaluation of limited-term community initiatives that are implemented within an environment of dynamic uncertainty. The principles of developmental evaluation can provide an epistemological foundation to an evaluation that is also bound by the pragmatics of more traditional approaches to evaluation, accountability requirements, and timelines. More specifically, these principles can substantially augment RBA approaches in a manner that supports learning and development, as well as identifying stories of change. Within this process, however, there are some tensions and challenges that are important to acknowledge.

Placing an RBA framework within the context of a developmental approach has the potential to cause epistemological conflicts. Some evaluators or funders with strong epistemological views may also oppose the integration of such approaches, just as some researchers oppose the integration of different research epistemologies through mixed methods (Creswell, Klassen, Plano Clark, and Smith, 2011). For the projects discussed here the integration of the two approaches was useful for two key reasons. First, RBA provided a simple framework to guide community projects in identifying key indicators to understand the implementation and achievements of their work. Secondly, and arguably more importantly, developmental evaluation enabled an expansion of the RBA framework that supported the projects to recognise and acknowledge the complexity and contexts that they were working in. Moreover, developmental evaluation allowed projects to respond to their learning through evaluation by adapting and developing their approaches during implementation.

Another challenge arose from the role of the evaluators. Patton (2011) identifies the role of the evaluators in developmental evaluation. He describes them as an active part of the team asking evaluative 
questions to stimulate learning; a strategic learning partner. Although this was achieved at the level of the funds, the variable engagement in the evaluation activities by some projects meant that this was not consistently achieved for all projects. The scope of the evaluation also played a role here, as it was not feasible to provide in-depth evaluation support throughout the country. The ability to reconcile this tension was heavily influenced by the engagement or evaluation readiness of the project leaders (Clinton, 2001; Stockdill, Baizerman, and Compton, 2002). Although the very essence of developmental evaluation supports the notion of evaluation capability building, our experience suggests that regular stakeholder and evaluator engagement is needed to maximise the potential value of a developmental approach. Some stakeholders will also require more support than others to embrace both the value of evaluation and the principles of a developmental approach. Therefore, funders and evaluators need to consider if the time and resources available will support and derive the value from such an approach.

Developmental evaluation can provide projects with opportunities for learning and adaptation within the context of more traditional performance frameworks and contexts. This requires openness on the part of the funders, other stakeholders, and evaluators. The uncertainties of the project and evaluation approach need to be acknowledged. These uncertainties also need to be managed through regular feedback mechanisms and processes. These processes are important for supporting adaptation and change, as well as for identifying indicators and outcomes that can be used to credibly illustrate the value and achievements of projects.

In terms of evaluation theory, our experience has identified the value of developmental evaluation as an overarching theory that can support learning and accountability even when integrated with other more accountability-focused approaches. Further, when the 
pragmatics of an evaluation context limited the ability to undertake traditional linear data-collection approaches, our experience suggests that the principles of developmental evaluation are sufficient for broadening perspectives of data quality and value, and acting as a catalyst for learning, adaptation, and development. This potential is enhanced when supported by high levels of stakeholder engagement.

\section{Acknowledgements}

We gratefully acknowledge staff of the Ministry of Social Development who administer the Te Punanga Haumaru and Think Differently campaigns for funding evaluation activity, and to project leadership for their enthusiastic participation. We also acknowledge Angela Boswell in the development of this article, and the reviewers for Evaluation Matters.

\section{References}

Appleton-Dyer, S. (2012). Understanding the mechanisms and outcomes of evaluation influence. Unpublished doctoral thesis, University of Auckland.

Appleton-Dyer, S., Clinton, J., Carswell, P., \& McNeill, R. (2012).

Understanding evaluation influence within public sector partnerships. American Journal of Evaluation, 33(4), 532-546.

https://doi.org/10.1177/1098214012447672

Appleton-Dyer, S., Edirisuriya, N., Field, A., \& Boswell, A. (2015). Think differently case study: Summary report. Retrieved from http://www.thinkdifferently.org.nz/resources.

Appleton-Dyer, S. \& Field, A. (2014). Understanding the factors that lead to social exclusion of disabled people. Auckland: Synergia.

Brennan, K. (2013). Developmental evaluation: An approach to evaluating complex social change initiatives. Next Generation Evaluation: Embracing Complexity Connectivity and Change: Stanford, CA. Retrieved from http://www.fsg.org/Portals/0/Uploads/Documents/PDF/Developmental_ Evaluation_Brennan.pdf 
Creswell, J. W., Klassen, A. C., Plano Clark, V. L., \& Smith, K. C. (2011). Best practices for mixed methods research in the health sciences. Bethesda, MD: National Institutes of Health. https://doi.org/10.1037/e566732013-001

Clinton, J. (2001). The power of "evaluation readiness" in program evaluation. Australian Evaluation Society. Canberra: UNITEC Institute of Technology. Retrieved from http://aes.asn.au/conferences/2001/ refereed\%20papers/Clinton.pdf

D’Anjou, L., \& Van Male, J. (1998). Between old and new: Social movements and cultural change. Mobilization: An International Quarterly, 3, 207-226.

Diaz-Puente, J., Yague, J., \& Afonso, A. (2008). Building evaluation capacity in Spain: A case study of rural development and empowerment in the European Union. Evaluation Review, 32, 478-506. https://doi.org/10.1177/0193841X08319015

Friedman, M. (2005). Trying hard is not good enough: How to produce measurable improvements for customers and communities. Victoria, BC: Trafford.

Gravitas Research and Strategy. (2005). Strategies with kids—information for parents (SKIP) research report. Auckland: Author.

House, E. (1991). Evaluation and social justice: Where are we? In M. McLaughlin, \& D. Phillips (Eds.), Evaluation and education: At quarter century (pp. 233-247). Chicago, IL: National Society for the Study of Education.

Keck, M., \& Sikkink, K. (2000). Historical precursors to modern transnational social movements and networks. In J. Guidry, M. Kennedy \& M. Zald (Eds.), Globalizations and social movements. culture, power and the transnational public sphere. Ann Arbour, MI: University of Michigan.

Levitas, R., Pantazis, C., Fahmy, E., Gordon, D., Lloyd, E., \& Patsios, D. (2007). The multi-dimensional analysis of social exclusion. Bristol, UK: University of Bristol. 
Maani, K., \& Cavana, R. (2007). Systems thinking, system dynamics: Managing change and complexity. Auckland: Prentice Hall.

McCammon, H. (2003). "Out of the parlors and into the streets":

The changing tactical repertoire of the U.S. women's suffrage movements. Social Forces, 81, 787-818. https://doi.org/10.1353/sof.2003.0037

McDonald, H. (2016). Developmental evaluation: A tool to support innovation. Evaluation Matters_He Take Tó Te Aromatawai, 2, 79-97. https://doi.org/10.18296/em.0012

Meadows, D. H. (2008). Thinking in systems. Vermont: Chelsea Green Publishing.

Ministry of Social Development. (2014). Think differently: Year in review 2013. Wellington: Author.

Ministry of Social Development. (2015). Te punanga haumaru: Strong families and communities where kids thrive. Retrieved from www.tph.org.nz

Patton M.Q. (1994). Developmental evaluation. American Journal of Evaluation, 15, 311-319. https://doi.org/10.1177/109821409401500312

Patton, M.Q. (2011). Developmental evaluation: Applying complexity concepts to enhance innovation and use. New York, NY: Guildford Press.

Patton, M.Q., McKegg, K., \& Wehipeihana, N. (2015). Developmental evaluation exemplars: Principles in practice. New York, NY. Guildford Press.

Patton, M. Q. (2015). The developmental evaluation mindset: Eight guiding principles. In M.Q. Patton, K. McKegg, \& N. Wehipeihana. (2015). Developmental evaluation exemplars: Principles in practice. New York, NY. Guildford Press.

Pinquart, M., \& Silbereisen, R. (2004). Human development in times of social change: Theoretical considerations and research needs. International Journal of Behavioral Development, 28(4), 289-298.

https://doi.org/10.1080/01650250344000406

Point Research. (2010). An innovative approach to changing social attitudes around family violence in New Zealand: Key ideas, insights and lessons learnt. Auckland: Point Research. 
Poister, T. (2003). Measuring performance in public and nonprofit organizations. San Francisco, CA: Jossey-Bass.

Preskill, H., \& Beer, T. (2012). Evaluating social innovation. FSG: Centre for Evaluation Innovation. https://doi.org/10.22163/fteval.2012.119

Ryan, D. and Shea, S.(2012). Results based accountability: Guidelines and resources. Ministry of Social Development, New Zealand. Retrieved from http://www.familyservices.govt.nz/working-with-us/fundingand-contracting/results-based-accountability/resources/guidelines/ introduction.html

Schama, S. (2009). The American future: A history. New York, NY: Harper Collins.

Senge, P. (1990). The fifth discipline: The art and practice of the learning organisation. London: Random House.

Shadish, W., Cook, T., \& Leviton, L. (1991). Foundations of program evaluation: Theories of practice. Newbury Park, CA: Sage.

Stockdill, S., Baizerman, M., \& Compton, D. W. (2002). Toward a definition of the ECB process: A conversation with the ECB literature. New Directions for Evaluation, 93, 7-26. https://doi.org/10.1002/ev.39

Szreter, S. (1988). The importance of social intervention in Britain's mortality decline c.1850-1914: A re-interpretation of the role of public health. Social History of Medicine, 1, 1-37. https://doi.org/10.1093/shm/1.1.1

Vaughan, G., \& Hansen, C. (2004). "Like minds, like mine": A New Zealand project to counter the stigma and discrimination associated with mental illness. Australasian Psychiatry, 12(113), 7. https://doi.org/10.1080/j.1039-8562.2004.02083.x

Westley, F., Zimmerman, B., \& Patton, M. (2006). Getting to maybe: How the world is changed. Toronto, ON: Vintage Canada.

Wholey, J., Abramson, M., \& Bellavita, B. (1986). Performance and credibility: Developing excellence in public and nonprofit organizations. Lexington, KY: DC Heath. 


\section{The authors}

Dr Sarah Appleton-Dyer: General Manager, Synergia Ltd, P.O. Box 147 168, Ponsonby, Auckland 1144, Aotearoa New Zealand.

Email: sarah.appleton@synergia.co.nz

Dr Adrian Field: Director, Dovetail Consulting Ltd, PO Box 78-146, Grey Lynn, Auckland 1245, Aotearoa New Zealand. Email: adrian@dovetailnz.com 